\title{
Improvement of Praxis Skills in Children with Hemiplegic Cerebral Palsy by Using New Trend of Augmented Visual and Auditory Feedback Training: A Case Report
}

\author{
Safaa M. ElKholi1, Reham S. Alsakhawi2 ${ }^{*}$ \\ ${ }^{1}$ Rehabilitation Sciences Department, College of Health and Rehabilitation Sciences, Princess Nourahbint Abdulrahman \\ University, Riyadh, Saudi Arabia \\ ${ }^{2}$ Department of Physical Therapy for Growth and Developmental Disorders in Children and its Surgery, Faculty of Physical \\ Therapy, Cairo University, Cairo, Egypt \\ Email: *rsm211_pt@yahoo.com
}

How to cite this paper: ElKholi, S.M. and Alsakhawi, R.S. (2018) Improvement of Praxis Skills in Children with Hemiplegic Cerebral Palsy by Using New Trend of Augmented Visual and Auditory Feedback Training: A Case Report. Open Journal of Therapy and Rehabilitation, 6, 43-55. https://doi.org/10.4236/ojtr.2018.62004

Received: March 2, 2018

Accepted: April 23, 2018

Published: April 26, 2018

Copyright $\odot 2018$ by authors and Scientific Research Publishing Inc. This work is licensed under the Creative Commons Attribution International License (CC BY 4.0).

http://creativecommons.org/licenses/by/4.0/

(c) (i) Open Access

\begin{abstract}
Aims: The aim of the study is to investigate if the new method of auditory and visual biofeedback as Upper Limb Exercise may improve praxis skills alone without any traditional physical therapy treatment or not and within three successive months of treatment in children with hemiplegic cerebral palsy. Methods: A 6-year-old hemiplegic cerebral palsied child was treated with Upper-Limb Exerciser as one of augmented visual and auditory feedback devices. Sensory Integration and Praxis test was used to measure a child's ability to integrate sensory input for perception, motor planning, and spatial actions in; Space Visualization, Figure-Ground Perception, Standing and Walking Balance, Design Copying, Postural Praxis, Bilateral Motor Coordination, Constructional Praxis, Postrotary Nystagmus, Motor Accuracy, Sequencing Praxis, Oral Praxis, Manual Form Perception, Kinesthesia, Finger Identification, Graphethesia, Localization of Tactile Stimuli, and Praxis on Verbal Command. Results: The results revealed improvement of the major standard score for each of the 17 subtests of Sensory Integration and Praxis Test when compared after three successive treatment. Conclusion: The using upper limb exerciser as one method of augmented visual and auditory feedback can be used as one of the physical and occupational therapy programs aiming to improve praxis skills in hemiplegic cerebral palsied children.
\end{abstract}

\section{Keywords}

Augmented Visual and Auditory Feedback, Cerebral Palsy, Dyspraxia, E-Linked Upper Limb Exerciser, Hemiplegia, Sensory Integration and Praxis Test 


\section{Introduction}

This study was focused on the most common subtype of cerebral palsy (CP), spastic hemiplegia affecting more than $38 \%$ of cases of CP [1] [2], which occur as a result of unilateral lesions to the cerebral cortex or corticospinal pathways [3]. The most common long-term functional deficits in these cases include impaired control of muscle tone and spasticity in the upper and lower extremities contralateral to the brain lesion, dyspraxia and intellectual disability considered as associated problems of hemiplegic cerebral palsy ( $15 \%-20 \%$ of cases) [2].

The ability to conceptualize, plan, and execute a non-habitual motor act is called Praxis. Praxis Problems are often referred to as dyspraxia [4] [5]. Dyspraxia is a disorder influencing the management of movements commonly used for daily activities (washing, dressing, tying shoelaces, using cutlery or other tools, etc.) and to accomplish expressive gestures (those aimed at communication), be they linked to the use of an object, therefore transitive, or abstract and with a symbolic content, therefore intransitive [6] [7]. Dyspraxia in hemiplegic $\mathrm{CP}$ mainly assumes the character of constructional apraxia. Specific disorders in visuoconstructive activities, such as reproducing spatial configurations with square blocks, drawing from a model, or spontaneous drawing, have been demonstrated in patients with right-side and left-side hemiplegia [8] [9]. Impairment of visual perception and eye-hand coordination are common in hemiplegic $\mathrm{CP}$ children [10]. They have difficulty performing accurate visually-guided movement [11] [12] [13], which could be due to deficits in oculomotor [8] [14], manual motor control [11] [12] [13] or anticipatory postural responses [15].

Deficits in the feedback process lead to the problem in monitoring and modifying motor activities. Several studies have indicated the effectiveness of augmented feedback, which is provided to the subject by an external signal device, to improve functional activities [16] [17]. It has been reported that augmented feedback can be used to achieve the goal set by the trainer or therapist faster, to increase the subject's level of motivation, it can be also used as reinforcement [17] [18] [19]. The augmented feedback was used with stroke [20] [21] [22], Parkinson [23], Traumatic Brain Injury [20], Spinal Cord Injury patients, and healthy individuals [16] [18] [24] [25] to improve motor learning. The mode of feedback in the previously mentioned studies varied between visual [16] [17] [18] [19], auditory [16] [18], or haptic [16] [19] feedback.

The available studies on $\mathrm{CP}$ children were designed to investigate the effect of auditory or visual augmented feedback on tracing line drawing task [26], upper limb performance and hand function [27] or treatment of equines gait [28]. To our knowledge, the new method of augmented visual feedback training by using Upper Limb Exerciser to improve different types of praxis skills has not been investigated on hemiplegic CP patients. The main objective of this study is to investigate the effectiveness of visual and auditory augmented feedback by using Upper Limb Exerciser system alone without any traditional physical therapy treatment within three successive months of treatment in hemiplegic $\mathrm{CP}$ children with dyspraxia. 


\section{Case Presentation}

A child whose name is B. N., whise age is 6 years old and 5 months and has been diagnosed with right side spastic hemiplegic cerebral palsy was included in this study. A detailed history gathered from the B.N.'s mother revealed that B. N. was a product of cesarean section after a full-term pregnancy. Gestational diabetes mellitus was the history of his mother. Birth weight was $3 \mathrm{~kg}$ with no complication. B.N. was discharged with normal feeding. At the age of 6 months, B.N. was noticed to have right sided weakness of the arm and leg. The degree of spasticity was 1+ grade according to Modified Ashwarth Scale [29]. According to Manual Ability Classification System (MACS) [30], the level of B.N. to handle objects independently was level II. He was able to understand and follow verbal commands and instructions included in both test and training, and he was free from any visual and/or auditory defects, significant tightness and/or fixed deformity of both upper limbs.

The participated child was assessed by Sensory Integration and Praxis test [31] before and after three successive treatment program in Disabled Child Association, Riyadh, KSA. The total time required for evaluating was average $120 \mathrm{mi}-$ nutes. The procedures followed were in accordance with the Institutional Ethical Committee Clearance, and written informed consent was taken from his parent. The treatment sessions started in February 2017 and ended in May 2017. B.N. received 60 minutes of the treatment session, three times per week for a period of three successive months [27]. No additional physical therapy exercises were included in the treatment sessions.

Sensory Integration and Praxis Test (SIPT): The SIPT is suitable for children ages four to nine years who have learning or developmental delays, particularly in praxis (motor planning) or tactile or visual discrimination. The Sensory Integration and Praxis is a standardized battery of 17 tests used to identify and measure sensory integration functions in children aged four to nine years [31]. According to Mulligan [32], the test measures specific areas of praxis and sensory processing including somatosensory (tactile) processing, the processing of vestibular and kinesthetic sensory information, bilateral integration and sequencing, praxis or motor planning abilities, form and space perception, and visual-motor skills.

The SIPT is one of the most commonly used assessments with a referenced norm. The SIPT has been standardized, and each of the 17 tests has strong evidence of both interrater and test-retest reliability [33]. SIPT is designed to assess praxis, various aspects of sensory processing, and the integration of sensory inputs [31] [33]. According to Ayres [31] and Changa, \& Yub [34], the SIPT measures the sensory integration processes that underlie learning a behavior, in addition, the tests assessing tactile and kinesthetic perception and standing balance with eyes closed.

Seventeen subtests were used to measure a child's ability to integrate sensory 
input for perception, motor planning, and spatial actions in [31]; Space Visualization (SV); require visual space perception and mental manipulation of objects in space, Figure-Ground Perception (FG); the child able to separate a foreground figure from a rival background, Standing and Walking Balance (SWB); ability of the child to balance on one or both feet, both statically and dynamically with eyes open and eyes closed, Design Copying (DC); accuracy and approach in copying designs, Postural Praxis (PPr); facility in assuming different and unusual body postures, Bilateral Motor Coordination (BMC); imitation of smoothly executed movements with both hands and both feet, Constructional Praxis (CP); skills in three-dimensional construction, Postrotary Nystagmus (PRN); records the duration of the oculomotor reflex following 10 rotations of the body in 20 seconds, Motor Accuracy (MAc); the child able to draw a red line over a heavy, curved black line, Sequencing Praxis (SPr); competency in perceiving, remembering, and executing a series of hand and finger movements, Oral Praxis (OPr); ability to imitate movements and positions of the tongue, blips, and jaws, Manual Form Perception (MFP); the child able to identify by pointing, the visual counterparts of various plastic geometric forms held and manipulated one at time in the hand, Kinesthesia (KIN); Somatic perception of arm position and movement, Finger Identification (FI); the child points to or touches the finger(s) previously touched by the examiner, Graphethesia (GRA); the child was asked to duplicate a design that was traced on the back of the child's hand by the examiner, Localization of Tactile Stimuli (LTS); the child able to place his finger on the spot on the child's hand or arm that previously was touched by the examiner, and Praxis on Verbal Command (PrVC); the child's ability to translate verbal commands into practice acts.

Figure 1(a), Figure 1(b) and Figure 2(a), Figure 2(b) showed examples of SIPT tests. The SIPT tests have generally fallen under the following four overlapping types: Motor-free visual perception; Somatosensory; Praxis; and Sensorimotor; Activities that involve bilateral coordination, balance, eye-hand coordination and vestibular system performance are used for testing.

E-linked Upper Limb Exerciser (E4000, Biometrics Ltd, Newport, Gwent, UK) [27]: is an interactive system providing motivation and feedback, increasing patient compliance and tolerance of exercise programs, allowing longer effective therapy. It is a computerized graded exerciser utilizing activities for therapeutic use. The activities may be controlled by a variety of devices, depending
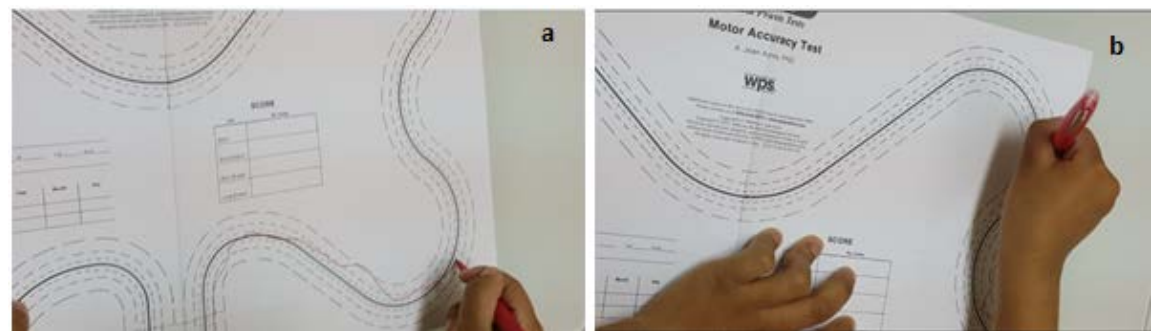

Figure 1. Child completed MAc test. 

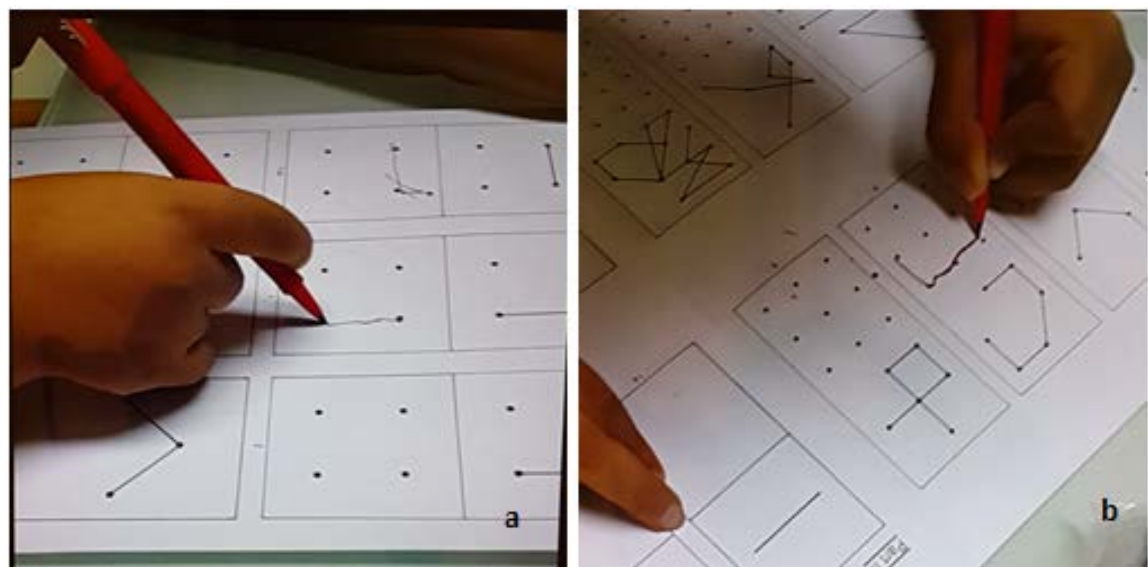

Figure 2. Child completed DC test.

upon the patient's physical and cognitive status. The exercises in the E-Link Upper Limb Exerciser System are in the form of simple and exciting games such as soccer, hitting walls, space shooting, driving, and throwing balls into a bucket.

In the E-Link Upper Limb Exerciser, playing games need movement reactions in response to visual stimuli, that is, patients understand changes in the game situation through looking into the screen and for continuing and succeeding in the games, make appropriate movement responses through upper limb exerciser. For example, to prevent an accident with humans, cars, and animals, driving in the correct lane in the driving exercise, the child should give appropriate reactions to the environmental barriers through moving the handle of the upper limb exerciser.

The Upper Limb Exerciser uses a variety of handles (spade, spade grip, cylinder, key handle, and disc tools). The child presented visual aspects of the environment on a large flat screen through a projector; at the same time, auditory feedback was delivered through the system speakers. The participated child in this study was instructed about how to use the E-Link Upper Extremity Exercise Program before he started the program. Figure 3 and Figures 4(a)-(c) showed examples of different types of games and Tool Handles were used in this study.

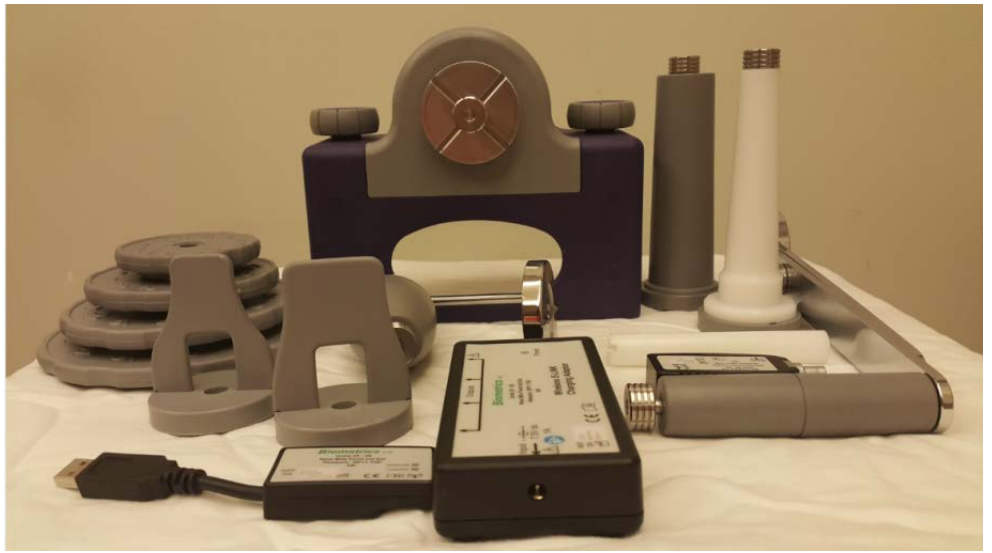

Figure 3. E-Link upper limb exerciser device. 

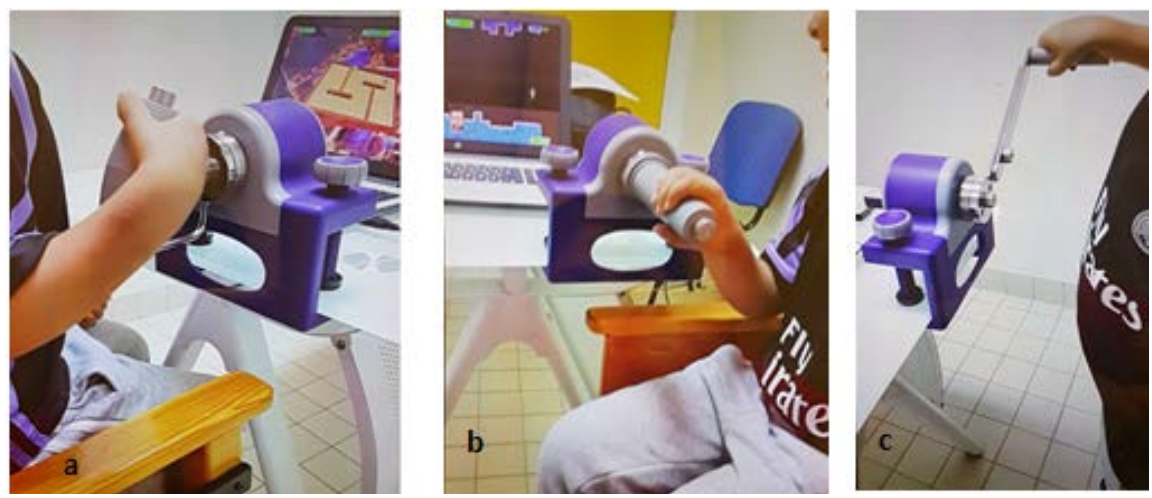

Figure 4. The child used E-Link upper limb exerciser for treatment.

\section{Outcomes}

Results from the pretest and posttest SIPT are displayed in Figure 5 and Table 1(a) and Table 1(b), SIPT pretreatment scores indicated difficulty with visuopraxis processing, in particular, DC $(-1.1)$, MFP $(-0.99)$ and $\mathrm{CPr}(-0.95)$. $\mathrm{He}$ also demonstrated difficulty in somatopraxis as measured by $\operatorname{PPr}(-2.11)$, GRA (-0.97), OPr (-0.85) and CPr. Moreover, B. N. had problems in somatosensory and tactile processing in KIN (0.99), FI (-0.9), LTS $(-1.2)$ and MFP. The results of pre-treatment scores illustrated the problems in bilateral integration and sequencing, especially in BMC $(-1.34) \operatorname{SPr}(-1.84)$, SWB $(-2.21)$, in addition, GRA, PPr, and OPr.

As shown in Figure 5 and Table 1(a) and Table 1(b), B.N. showed highly improvements on six of six praxis tests $(\mathrm{DC}$ : pretest $=-1.1$, posttest $=-0.24$; PPr: pretest $=-2.11$, posttest $=-0.9$; OPr: pretest $=-0.85$, posttest $=-0.2$; SPr: pretest $=-1.84$, posttest $=-0.6$; CPr: pretest $=-0.95$, posttest $=-0.1$ PrVC: pretest $=-0.98$, posttest $=-0.1$ ). In addition, he improved on two of four SIPT form and space perception tasks (SV: pretest $=0.29$, posttest $=0.62$; FGP: pretest $=$ -0.5 , posttest $=0.2$ ). On three of five SIPT bilateral integration and sequencing tests, B.N. showed improvements in BMC (pretest $=-1.34$, posttest $=-0.36$ ) and the previously described OPr and SPr.

Less improvement scores on SIPT somatic and vestibular sensory processing tests $(\mathrm{KIN}$ : pretest $=-0.99$, posttest $=-0.87$; FI: pretest $=-0.9$, posttest $=-0.68$; GRA: pretest $=-0.97$, posttest $=-0.77$; LTS: pretest $=-1.2$, posttest $=-0.86$; PRN: pretest $=-0.15$, posttest $=0.12$; SWB: pretest $=-2.21$, posttest $=-1.8$ ) illustrated in figure and table comparing to the previous results. In addition, less improvements on two of four SIPT form and space perception tasks illustrated in figure and table comparing to the previous results (MFP: pretest $=-0.99$. posttest $=-0.8$; MAc: pretest $=-0.24$, posttest $=-0.1$ ).

According to Ayres [31], no score has appeared if the test was not administered, or if the test was partially administered in such a way that the major score could not be computed. The SD scores indicated compare to a metric usually associated with the normal curve and are also known as z-scores. In a normal distribution, SD scores have an average or mean value of 0 and a standard deviation 


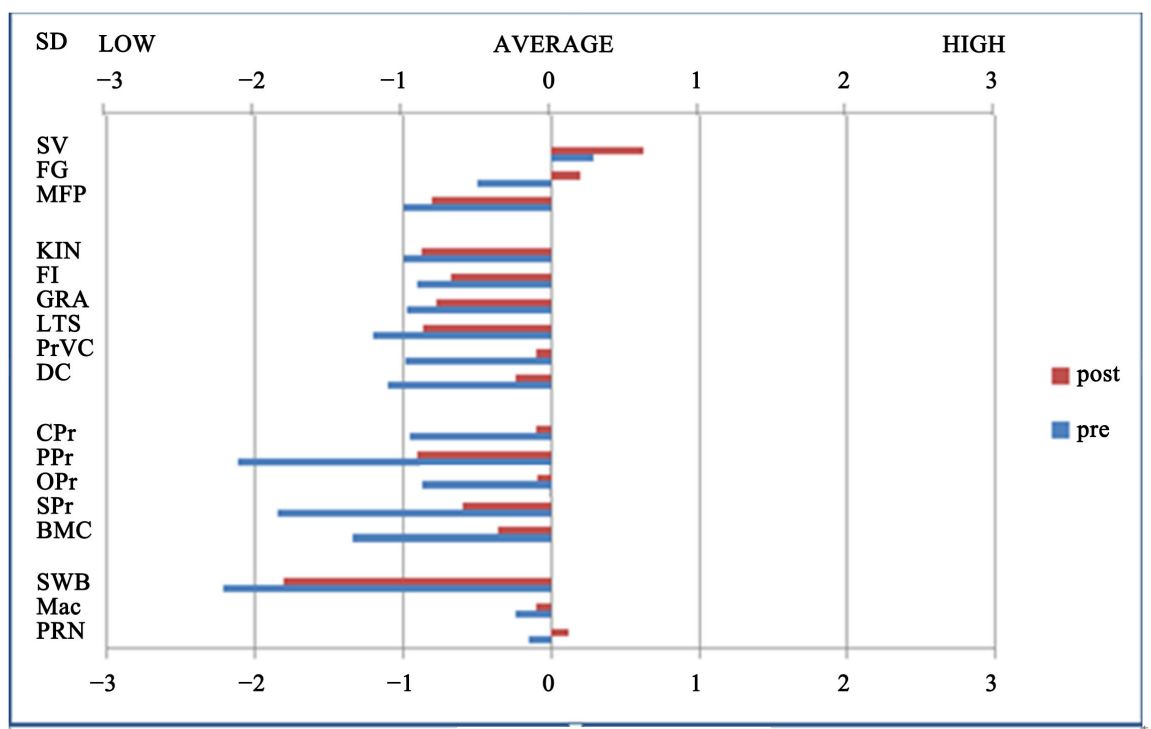

Figure 5. Major scores (SD) of 17 subtests of SIPT before and after three months of treatment.

Table 1. Comparison between major scores of SIPT.

(a)

\begin{tabular}{cccccccccc}
\hline & SV & FG & MFP & KIN & FI & GRA & LTS & PrVC & DC \\
\hline Pre & 0.29 & -0.5 & -0.99 & -0.99 & -0.9 & -0.97 & -1.2 & -0.98 & -1.1 \\
Post & 0.62 & 0.2 & -0.8 & -0.87 & -0.68 & -0.77 & -0.86 & -0.1 & -0.24 \\
\hline
\end{tabular}

Pre: before three months of treatment; Post: after three months of treatment; SV: Space Visualization; FG: Figure-Ground Perception; MFP: Manual Form Perception; KIN: Kinesthesia; FI: Finger Identification; GRA: Graphethesia; LTS: Localization of Tactile Stimuli; PrVC: Praxis on Verbal Command; DC: Design Copying

(b)

\begin{tabular}{ccccccccc}
\hline & CPr & PPr & Opr & SPr & BMC & SWB & MAc & PRN \\
\hline Pre & -0.95 & -2.11 & -0.85 & -1.84 & -1.34 & -2.21 & -0.24 & -0.15 \\
Post & -0.1 & -0.9 & -0.2 & -0.6 & -0.36 & -1.8 & -0.1 & 0.12 \\
\hline
\end{tabular}

Pre: before three months of treatment; Post: after three months of treatment; CPr: Constructional Praxis; PPr: Postural Praxis; OPr: Oral Praxis; SPr: Sequencing Praxis; BMC: Bilateral Motor Coordination; SWB: Standing and Walking Balance, MAc; Motor Accuracy; PRN: Postrotary Nystagmus.

of 1 . The SD score ranges for the SIPT can be interpreted as follows: 1) a score of -3.0 to -2.5 demonstrates severe dysfunction; 2 ) a score of -2.5 to -2.0 shows definite dysfunction; 3 ) a score of -2.0 to -1.0 shows mild dysfunction or mild difficulty; 4 ) a score of -1.0 to +1.0 shows functioning typically for the child's age; 5 ) a score of +1.0 to +2.0 indicates above average functioning; and 6 ) a score of +2.0 to +3.0 indicates advanced functioning. Test scores above $3.00 \mathrm{SD}$ are accounted for 3.00 and scores below -3.00 are accounted as -3.00 .

\section{Discussion}

The present study was essentially intended to optimize that if the Upper Limb 
Exerciser as the new trend of augmented visual and auditory feedback program has an effect on dyspraxia in spastic hemiplegic children alone without any traditional physical therapy program. Meanwhile, attempts to coordinate sensory input for motor planning, perception, and spatial actions of spastic hemiplegic children were done to investigate any concomitant improvement occurred in the sensory integration abilities.

According to Mulligan [35] and Jaarsveld et al. [36], BMC, OPr, and SWB are three tests that, when scores are low, add to the conclusion of a Bilateral Integration deficit. The two tests also were used in the diagnosis of Soma to Dyspraxia are OPr and SWB. The same can be said for the diagnosis of Soma to Dyspraxia. A diagnosis of visual dyspraxia are made, as they are two of four of the major scores considered for diagnosing this dysfunction, tests are CPa, MA, SV, DC, FGP, and MFP. CPa and DC assessed Visuoconstruction skills.

The outcomes showed before the treatment difficulty with visuopraxis and somatopraxis processing, in particular tests which agreement with Gordon et al. [37], they mention that the hemiplegic children have deficits in proprioceptive and visual-spatial information integration and sensorimotor integration. In addition, the difficulty of somatosensory, tactile processing and bilateral integration and sequencing of B.N. was supported by Sakzewski et al. [38]. They mention that the sensory deficits of proprioception and tactile perception is also common leading to limitations on manual actions performed with the affected hand, specifically fine motor skills such as grasping and manipulation. Deficits in eye-hand coordination lead to exacerbation of the involved hand dysfunction limiting the child's activities, participation, and quality of life [37].

It is generally assumed that any neurologically intact person performing a task that requires eye-hand coordination need a continuous visual, tactile, proprioception and kinesthetic feedback in order to monitor and modify the movement when necessary. Feedback on performance is essential in skill acquisition. With injuries or diseases that affect the central nervous system the intrinsic feedback mechanisms are often impaired and so extrinsic (or augmented) feedback is of great importance for motor relearning. Therefore, eye-hand coordination impairments lead to difficulties in accepting different types of sensory information from the external environment and cause limitation in upperlimb functional performance [39].

The general improvement of praxis, form and space perception, and bilateral integration and sequencing processes after three successive treatment program by using E-link upperlimb exerciser as augmented visual and auditory biofeedback was shown in results of this study. This result may be attributed to the E-link upper limb exerciser could display augmented visual and auditory information during the performance. This kind of "augmented information" may assist in children's searching strategies to find the "solution" to performing a task. That is, children may perceive the visual information provided by the displayed hand on the screen and use this information for their later actions to gradually search for efficient reaching patterns. Moreover, the upper limb exerciser used in 
our study allowed the task difficulties of the games to be adjusted according to an individual child's motor abilities and gradually offered to children with $\mathrm{CP}$ step-by-step guidance for achieving efficient reaching patterns.

In addition, E-link Upper Limb Exerciser may improve eye-hand coordination by improving the following sequence: visual detection of the target; attention focusing; perceptual identification and location of the target; cognitive planning and programming of reaching movement; activation of arm muscles to initiate reaching. Such sequence involves the sensory and perceptual systems, arousal and motivational systems, central processing system and motor systems.

The most important different between E-Link Upper Limb Exerciser system and other visual and auditory augmented feedback devices that it has variety of resistance with variety of handle to deliver different types of grip and pinch exercises such as lateral pinch, tip-to-tip pinch, pad-to-pad pinch, spherical grasp, and cylindrical grasp, as well as movements of all upper limb joints using a functional approach rather than isolating individual joints which allow more motivation and attention during playing specifically when the resistance of handle grasp increased. E-Link is also a system with electronic instrumentation for both active and active resistive exercise of the upper extremities, isometric grip and pinch strength exercise.

Augmented feedback is much used to improve motor learning in the rehabilitation of persons with neurologic disorders. There are indications that application of augmented feedback in a task-oriented paradigm may help the recovery of sensorimotor functions and lead to adaptive plasticity in cortical and subcortical brain tissue [40]. Theoretically, the use of feedback during the execution of the movement or the function helps the acquiring of a motor ability, in that the controlling process changes gradually from a closed-loop system to an open-loop system using explicit or implicit learning [41].

According to Carr \& Shepherd [42], they stated that repetition is an important aspect of practice, and repetition of a task has been shown to improve performance in people with or without disabilities. Repetition can be described as repeated attempts to solve a goal related problem by building on previous attempts, that is, repetition without repetition. Repetitive practice enables the system to coordinate the muscular synergies that move the segmental linkage in a desired manner to accomplish the task goal. The child in this study repeated practicing to perceive the appearance of the target in various locations of the screen and then move their arms to quickly reach the target. By repeatedly practicing these activities, B.N. improved his performance in eye-hand coordination; this improvement was reflected in the scores of praxis tests.

The E-Link upper Limb Exerciser consists of a variety of activities which can exert similar cognitive demands on the child. These activities are timed, gradable in complexity, speed, duration, and feedback is available through assessment readings and scores so that child has an ongoing record of his performance which may enhance motivation. Motivation did seem to be a strong determining 
factor and one-to-one attention was often needed to encourage the child to try to reach the targets.

On the other hand, results showed less improvement of somatic and vestibular sensory processing that because of the E-link upper limb exerciser doesn't have used a static or dynamic force plate system to control child's postural sway or improve the static and dynamic stability of the childlike other augmented biofeedback devices. The E-link Upper Limb Exerciser system in this study can be used to improve sustained attention, decreased visual-spatial inattention and improved executive function.

Limitations of this study which reduce one's ability to generalize the results to a broader population include the small sample size. Although the limitations of a case report include lack of generalizability or ability to distinguish treatment effects from maturation effects, this case report represents one child in a larger randomized controlled trial that is currently ongoing. Other limitation can be found it in the current study is the follow-up the child. Over the next few years the authors plan to examine this training approach in a larger group of children using the Upper Limb Exerciser with or without traditional physical therapy treatment and foul-up the children.

\section{Conclusion}

On bases of the present data, it can be concluded that the Upper Limb Exerciser system can be used as a method of augmented visual and auditory biofeedback to improve praxis skills in hemiplegic cerebral palsied children, and it can be used by physical and occupational therapists to improve perception, motor planning, and spatial actions of hemiplegic cerebral palsied children.

\section{Acknowledgements}

The authors express their thanks to the participated child and his parent for their confidence and collaboration in this study. Grateful appreciation is due to Disabled Child Association, Riyadh, KSA, for unfailing efforts and valuable assistance that help completion of this study.

\section{Funding}

Self-funded.

\section{Declaration of Interest}

None.

\section{References}

[1] Johnson, A. (2000) Cerebral Palsies: Epidemiology and Causal Pathways. Archives of Disease in Childhood, 83, 279. https://doi.org/10.1136/adc.83.3.279a

[2] Cioni, G., Sgandurra, G., Muzzini, S., Paolicelli, P.B. and Ferrari, A. (2010) Forms of Hemiplegia. In: Ferrari, A. and Cioni, G., Eds., The Spastic Forms of Cerebral Palsy, Springer, 331. https://doi.org/10.1007/978-88-470-1478-7_16 
[3] Kwong, K.L., Wong, Y.C., Fong, C.M., Wong, S.N. and So, K. T. (2004) Magnetic Resonance Imaging in 122 Children with Spastic Cerebral Palsy. Pediatric Neurolo$g y$, 31, 172-176. https://doi.org/10.1016/j.pediatrneurol.2004.02.005

[4] Parham, L.D. and Mailloux, Z. (2010) Sensory Integration. In: Smith, J.C. and O'Brain, J.C., Eds., Occupational Therapy for Children, 6th Edition, Elsevier Inc., 349-355.

[5] Anderson-Mooney, A.J., et al. (2016) Gait Dyspraxia as a Clinical Marker of Cognitive Decline in Down Syndrome: A Review of Theory and Proposed Mechanisms. Brain and Cognition, 104, 48-57. https://doi.org/10.1016/j.bandc.2016.02.007

[6] Ferrari, A. (2010) Motor Defects. In: Ferrari, A. and Cioni, G., Eds., The Spastic Forms of Cerebral Palsy, Springer, 60-61.

https://doi.org/10.1007/978-88-470-1478-7_4

[7] Miller, M., Chukoskie, L., Zinni, M., Townsend, J. and Trauner, D. (2014) Dyspraxia, Motor Function and Visual-Motor Integration in Autism. Behavioural Brain Research, 269, 95-102. https://doi.org/10.1016/j.bbr.2014.04.011

[8] Kozeis, N., Anogeianaki, A., Mitova, D.T., Anogianakis, G., Mitov, T. and Klisarova, A. (2007) Visual Function and Visual Perception in Cerebral Palsied Children. Ophthalmic and Physiological Optics, 27, 44-53. https://doi.org/10.1111/j.1475-1313.2006.00413.x

[9] Muzzini, S., Posteraro, F. and Leonetti, R. (2010) Praxic Organization Disorders In: Ferrari, A. and Cioni, G., Eds., The Spastic Forms of Cerebral Palsy, Springer, 99-123. https://doi.org/10.1007/978-88-470-1478-7_6

[10] Hung, Y.C., Charles, J. and Gordon, A.M. (2004) Bimanual Coordination during a Goal Directed Task in Children with Hemiplegic Cerebral Palsy. Developmental Medicine \& Child Neurology, 46, 746-753. https://doi.org/10.1111/j.1469-8749.2004.tb00994.x

[11] Chang, J.J., Wu, T.I., Wu, W.L. and Su, F.C. (2005) Kinematical Measure for Spastic Reaching in Children with Cerebral Palsy. Clinical Biomechanics (Bristol, Avon), 20, 381-388. https://doi.org/10.1016/j.clinbiomech.2004.11.015

[12] Mackey, A.H., Walt, S.E. and Stott, N.S. (2006) Deficits in Upper-Limb Task Performance in Children with Hemiplegic Cerebral Palsy as Defined by 3-Dimensional Kinematics. Archives of Physical Medicine and Rehabiltation, 87, 207-215. https://doi.org/10.1016/j.apmr.2005.10.023

[13] Ronnqvist, L. and Rosblad, B. (2007) Kinematic Analysis of Unimanual Reaching and Grasping Movements in Children with Hemiplegic Cerebral Palsy. Clinical Biomechanics (Bristol, Avon), 22, 165-175. https://doi.org/10.1016/j.clinbiomech.2006.09.004

[14] Salati, R., Borgatti, R., Giammari, G. and Jacobson, L. (2002) Oculomotor Dysfunctionin Cerebral Visual Impairment Following Perinatal Hypoxia. Developmental Medicine \& Child Neurology, 44, 542-550. https://doi.org/10.1111/j.1469-8749.2002.tb00327.x

[15] Van der Heide, J.C., Fock, J.M., Otten, B., Stremmelaar, E. and Hadders-Algra, M. (2005) Kinematic Characteristics of Reaching Movements in Preterm Children with Cerebral Palsy. Pediatric Research, 57, 883-889. https://doi.org/10.1203/01.PDR.0000157771.20683.14

[16] Sigrist, R., Rauter, G., Riener, R. and Wolf, P. (2013) Augmented Visual, Auditory, Haptic, and Multimodal Feedback in Motor Learning: A Review. Psychonomic Bulletin \& Review, 20, 21-53. https://doi.org/10.3758/s13423-012-0333-8 
[17] Chen, J.L., Fujii, S. and Schlaug, G. (2016) The Use of Augmented Auditory Feedback to Improve Arm Reaching in Stroke: A Case Series. Disability and Rehabilitation, 38, 1115-1124. https://doi.org/10.3109/09638288.2015.1076530

[18] Ronsse, R., Puttemans, V., Coxon, J.P., Goble, D.J., Wagemans, J., Wenderoth, N. and Swinnen, S.P. (2011) Motor Learning with Augmented Feedback: Modality-Dependent Behavioral and Neural Consequences. Cerebral Cortex, 21, 1283-1294. https://doi.org/10.1093/cercor/bhq209

[19] Molier, B.I., Van Asseldonk, E.H., Hermens, H.J. and Jannink, M.J. (2010) Nature, Timing, Frequency and Type of Augmented Feedback; Does It Influence Motor Relearning of the Hemiparetic Arm after Stroke? A Systematic Review. Disability and Rehabilitation, 32, 1799-1809. https://doi.org/10.3109/09638281003734359

[20] Platz, T., Winter, T., Müller, N., Pinkowski, C., Eickhof, C. and Mauritz, K.H. (2001) Arm Ability Training for Stroke and Traumatic Brain Injury Patients with Mild Arm Paresis: A Single-Blind, Randomized, Controlled Trial. Archives of Physical Medicine and Rehabilitation, 82, 961-968.

https://doi.org/10.1053/apmr.2001.23982

[21] Van der Lee, J.H., et al. (2001) Exercise Therapy for Arm Function in Stroke Patients: A Systematic Review of Randomized Controlled Trials. Clinical Rehabilitation, 15, 20-31. https://doi.org/10.1191/026921501677557755

[22] Armagan, O., Tascioglu, F. and Oner, C. (2003) Electromyographic Biofeedback in the Treatment of the Hemiplegic Hand: A Placebo-Controlled Study. American Journal of Physical Medicine \& Rehabilitation, 82, 856-861. https://doi.org/10.1097/01.PHM.0000091984.72486.E0

[23] Marchese, R., Diverio, M., Zucchi, F., Lentino, C. and Abbruzzese, G. (2000) The Role of Sensory Cues in the Rehabilitation of Parkinsonian Patients: A Comparison of Two Physical Therapy Protocols. Movement Disorders, 15, 879-883. https://doi.org/10.1002/1531-8257(200009)15:5<879::AID-MDS1018>3.0.CO;2-9

[24] Van Dijk, H. and Hermens, H.J. (2006) Effects of Age and Timing of Augmented Feedback on Learning Muscle Relaxation While Performing a Gross Motor Task. American Journal of Physical Medicine \& Rehabilitation, 85, 148-155. https://doi.org/10.1097/01.phm.0000197959.17247.5b

[25] Wu, W.F., et al. (2011) Contextual Interference and Augmented Feedback: Is There an Additive Effect for Motor Learning? Human Movement Science, 30, 1092-1101. https://doi.org/10.1016/j.humov.2011.02.004

[26] Talbot, M.L. and Junkala, J. (1981) The Effects of Auditorally Augmented Feedback on the Eye-Hand Coordination of Students with Cerebral Palsy. The American Journal of Occupational Therapy, 35, 525-528. https://doi.org/10.5014/ajot.35.8.525

[27] Rostami, H., Arastoob, A.A., Nejada, S.J., Mahanya, M.K., Malamiric, R.A. and Goharpeyb, S. (2012) Effects of Modified Constraint-Induced Movement Therapy Invirtual Environment on Upper-Limb Function in Children with Spastic Hemiparetic Cerebralpalsy: A Randomized Controlled Trial. NeuroRehabilitation, 31, 357-365.

[28] Conrad, L. and Bleck, E.E. (1980) Augmented Auditory Feedback in the Treatment of Equinus Gait in Children. Developmental Medicine \& Child Neurology, 22, 713-718. https://doi.org/10.1111/j.1469-8749.1980.tb03737.x

[29] Bohannon, R.W. and Smith, M.B. (1987) Interrater Reliability of a Modified Ashworth Scale of Muscle Spasticity. Physical Therapy, 67, 206-207. https://doi.org/10.1093/ptj/67.2.206

[30] Öhrvall, A.M., Krumlinde-Sundholm L. and Eliasson, A.C. (2013) Manual Ability Classification System (MACS); Evidence of Stability over Time. Developmental 
Medicine \& Child Neurology, 56, 185-189. https://doi.org/10.1111/dmcn.12348

[31] Ayres, A. (2004) Sensory Integration Praxis Test. Updated Edition, Western Psychological Services, Los Angeles.

[32] Mulligan, S. (2000) Cluster Analysis of Scores of Children on the Sensory Integration and Praxis Tests. The Occupational Therapy Journal of Research, 20, 256-270. https://doi.org/10.1177/153944920002000403

[33] Asher, A.V., Parham, L.D. and Knox, S. (2008) Interrater Reliability of Sensory Integration and Praxis Tests (SIPT) Score Interpretation. The American Journal of Occupational Therapy, 62, 308-319. https://doi.org/10.5014/ajot.62.3.308

[34] Changa, S. and Yub, N. (2018) Development and Validation of the Comprehensive Praxis Assessment for Children Aged 6-8. Human Movement Science. Science Direct, 57, 332-341. https://doi.org/10.1016/j.humov.2017.09.011

[35] Mulligan, S. (1998) Pattern of Sensory Integration Dysfunction: A Confirmatory Factor Analysis. American Journal of Occupational Therapy, 52, 819-828. https://doi.org/10.5014/ajot.52.10.819

[36] Jaarsveld, A., Mailloux, Z. and Herzberg, D.S. (2012) The Use of the Sensory Integration and Praxis Tests with South African Children. Journal of Occupational Therapy, 42, 12-18.

[37] Gordon, A.M., Charles, J. and Steenbergen, B. (2006) Fingertip Force Planning during Grasp Is Disrupted by Impaired Sensorimotor Integration in Children with Hemiplegic Cerebral Palsy. Pediatric Research, 60, 587-591. https://doi.org/10.1203/01.pdr.0000242370.41469.74

[38] Sakzewski, L., Ziviani, J. and Boyd, R. (2009) Systematic Review and Meta-Analysis of therapeutic Management of Upper-Limb Dysfunction in Children with Congenital Hemiplegia. Pediatrics, 123, e1111-e1122.

https://doi.org/10.1542/peds.2008-3335

[39] Shumway-Cook, A. and Woollacott, M.H. (2007) Motor Control: Theory and Practical Applications. 3rd Edition, Lippincott Williams \& Wilkins, Baltimore.

[40] Huang, H., Wolf, S.L. and He, J. (2006) Recent Developments in Biofeedback for Neuromotor Rehabilitation. Journal of Neuroengineering and Rehabilitation, 3, 11.

[41] Jonsdottir, J. and Cattaneo, D. (2014) Task-Oriented Biofeedback in Neurorehabilitation. In: Mostofsky, D.I., Ed., The Handbook of Behavioral Medicine, John Wiley \& Sons, Inc., Hoboken, 808. https://doi.org/10.1002/9781118453940.ch38

[42] Carr, J. and Shepherd, R. (2000) Movement Science: Foundations for Physical Therapy in Rehabilitation. 2nd Edition, Pro-Ed Publisher, Austin. 